\title{
Pathological alteration and therapeutic implications of sepsis-induced immune cell apoptosis
}

\author{
Chao Cao ${ }^{1,2,3}$, Muming $\mathrm{Yu}^{1}$ and Yanfen Chai $\mathbb{0}^{1,2}$
}

\begin{abstract}
Sepsis is a life-threatening organ dysfunction syndrome caused by dysregulated host response to infection that leads to uncontrolled inflammatory response followed by immunosuppression. However, despite the high mortality rate, no specific treatment modality or drugs with high efficacy is available for sepsis to date. Although improved treatment strategies have increased the survival rate during the initial state of excessive inflammatory response, recent trends in sepsis show that mortality occurs at a period of continuous immunosuppressive state in which patients succumb to secondary infections within a few weeks or months due to post-sepsis "immune paralysis." Immune cell alteration induced by uncontrolled apoptosis has been considered a major cause of significant immunosuppression. Particularly, apoptosis of lymphocytes, including innate immune cells and adaptive immune cells, is associated with a higher risk of secondary infections and poor outcomes. Multiple postmortem studies have confirmed that sepsis-induced immune cell apoptosis occurs in all age groups, including neonates, pediatric, and adult patients, and it is considered to be a primary contributing factor to the immunosuppressive pathophysiology of sepsis. Therapeutic perspectives targeting apoptosis through various strategies could improve survival in sepsis. In this review article, we will focus on describing the major apoptosis process of immune cells with respect to physiologic and molecular mechanisms. Further, advances in apoptosis-targeted treatment modalities for sepsis will also be discussed.
\end{abstract}

\section{Facts}

- Sepsis leads to uncontrolled inflammatory response with immunosuppression.

- Immune cell alteration induced by uncontrolled apoptosis is a major cause of profound immunosuppression.

- Therapeutic perspectives targeting apoptosis through various strategies could improve survival in sepsis.

\section{Open questions}

- It is known that apoptotic depletion of immune cells is responsible for immune dysfunction; however, how do immune cells, including innate and adaptive immune cells, change in the course of sepsis?

- What are the specific molecular mechanisms and interactions involved in the pathways mediating physiological alteration of immune cells?

- Are there specific pathways and related factors that can be diagnostic and therapeutic targets for sepsisinduced immunosuppression?

\section{Introduction}

Sepsis is a major public health challenge worldwide owing to protracted inflammation, immune suppression, susceptibility to infections, and even death ${ }^{1}$. Despite

\footnotetext{
'Tianjin Medical University General Hospital, Tianjin.cn)

${ }^{2}$ Tianjin Medical University, Tianjin, China

Full list of author information is available at the end of the article.

Edited by H.-U. Simon
} 
improvements in the understanding of the pathophysiology of sepsis and therapeutic strategies, no specific therapeutic agent for the treatment of sepsis has been approved to date ${ }^{2,3}$.

Sepsis treatment, including antibiotic therapies, ventilator management, blood glucose maintenance, and resuscitative strategies, has rapidly progressed ${ }^{4,5}$, particularly the supportive therapies recommended by the Surviving Sepsis Campaign ${ }^{6}$. However, few novel effective therapies have been identified, and the incidence of sepsis has increased ${ }^{7,8}$, with approximately 31.5 million cases of sepsis, 19.4 million severe sepsis, and 5.3 million deaths reported annually ${ }^{9}$. Sepsis with subsequent multiple organ dysfunction remains the leading cause of mortality in hospitalized patients, and it is projected to increase at an alarming rate over the next two decades ${ }^{10}$. Even more alarming is the increasing rate of sepsis-associated intensive care unit (ICU) mortality, which is the most common cause of death in ICU patients; severe sepsis accounts for $>50 \%$ of ICU mortality ${ }^{11}$. Patients with sepsis are also hospitalized longer and have an eight times higher risk of death during hospitalization than other inpatients ${ }^{12}$.

In general, the pathophysiology of sepsis is considered as an initial hyperinflammatory phase that lasts for several days followed by a more protracted immunosuppressive phase $^{13}$. The current death distribution indicates peaks during the early phase, although at a lower magnitude, and another peak after 2-3 months that continues to increase over the next 3 years $^{14,15}$ (Fig. 1). However, varying definitions and ineffective clinical strategies have led to discrepancies in the incidence and mortality rates of sepsis $^{16}$, and thus the criterion should be redefined ${ }^{17}$. In the third International Consensus for Sepsis and Septic Shock, sepsis was clinically defined as a life-threatening condition of organ dysfunction caused by a dysregulated immune response to infection ${ }^{18}$. These changes shift the focus of pathophysiology on sepsis-induced immune dysfunction and long-term outcomes of sepsis patients who survive from a fatal stage owing to sophisticated care in the $\mathrm{ICU}^{19}$. Sepsis can be considered as a race to death between the pathogens and host immune response, where the pathogens seek an advantage by incapacitating various aspects of host immunity ${ }^{20}$. Numerous studies have shown that a large number of patients who died of sepsis had unresolved opportunistic infections ${ }^{21,22}$ and immunosuppressive features ${ }^{10,23,24}$ (Fig. 2). Several mechanisms are responsible for sepsis-induced immunosuppression, including apoptotic depletion of immune cells, increased expression of negative costimulatory molecules, increased regulatory $\mathrm{T}$ (Treg) cell expression, expression of programmed cell death (PD)- 1 on $\mathrm{CD} 4^{+} \mathrm{T}$ cells, and cellular exhaustion $^{23}$. Of these, immune cell apoptosis has been increasingly recognized as a key factor in the pathophysiology of septic complications ${ }^{25-27}$.

Widespread lymphocyte apoptosis occurring in the lymphoid (spleen, thymus, and lymph nodes) and other organs $^{28}$ that results in impaired immune cell activity (including that of neutrophils, monocyte and macrophages, B cells, natural killer cells [NK cells], and

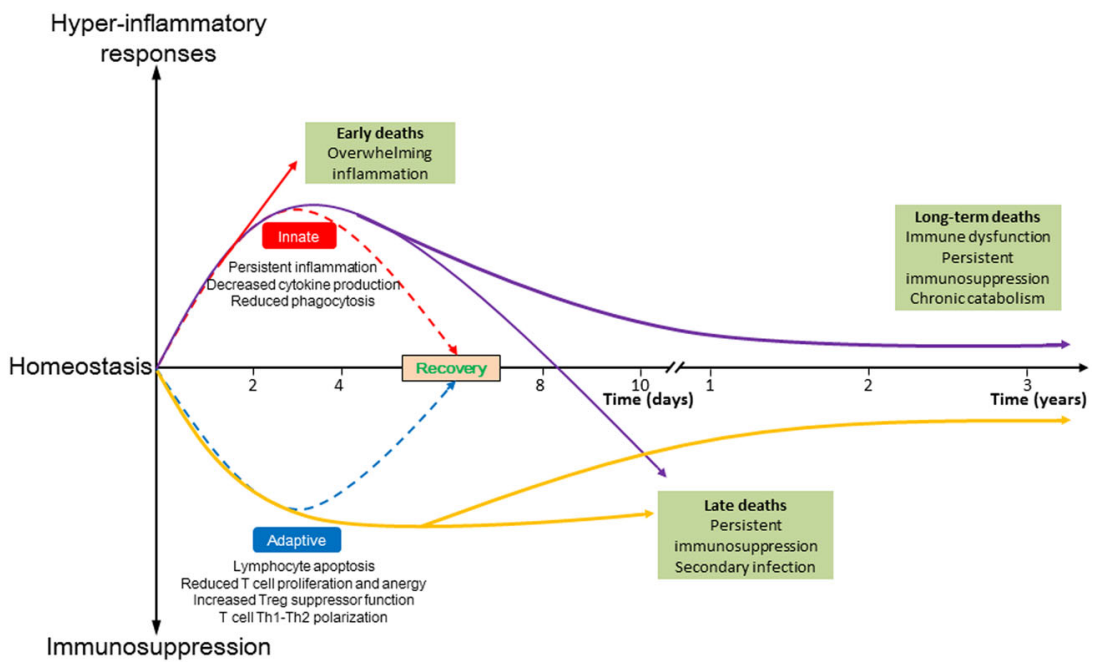

Fig. $1 \mathrm{Immune}$ response in sepsis. Early activation of both innate and adaptive immune response is involved in the pathogenesis of sepsis. The peak mortality rates during the early period (top red line) were due to overwhelming inflammatory response, also known as "cytokine storm," which comprises fever, refractory shock, inadequate resuscitation, and cardiac or pulmonary failure. Meanwhile, mortality at the later period is due to persistent immunosuppression with secondary infections that results in organ injury and/or failure. Although more sophisticated ICU care has improved mortality, patients still die at the later period or after several years owing to the persistent immunosuppression, immune dysfunction, or chronic catabolism 


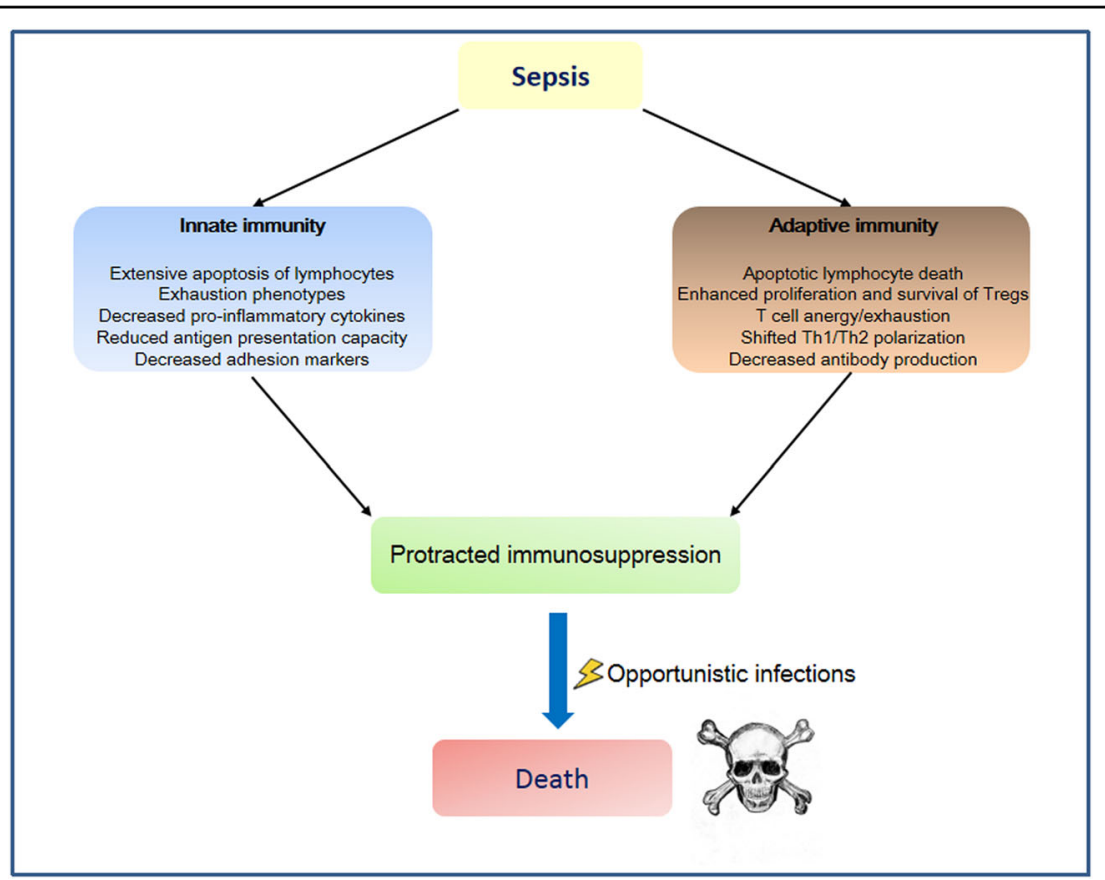

Fig. 2 Alterations in innate and adaptive immunity in the pathophysiology of sepsis. Early activation of innate immunity is the first line of defense against infection and plays a central role in the initiation of adaptive immunity. However, in sepsis, excessive immune responses lead to several alterations in innate and adaptive immunity that contribute to protracted immunosuppression and increase the risk for opportunistic infection. In some way, sepsis can be considered as a race to the death between host immune response and pathogens that seek an advantage by impairing the host immune defenses

dendritic cells [DCs]) is a crucial contributing factor to the development of the immunosuppressive phase of sepsis $^{29}$. Multiple studies have reported that preventing immune cell apoptosis could markedly improve survival $^{10,30,31}$. In this review, we will highlight the importance of sepsis-induced immune cell apoptosis, including the role of innate and adaptive immune cells in the pathogenesis of sepsis, alterations in their immune metabolic stage, and the clinical implications and potential therapeutic interventions.

\section{Apoptosis in sepsis}

Apoptosis is a tightly regulated form of cell death that is vital in both embryo implantation and development and turnover of tissues during maturation ${ }^{32}$. During sepsisinduced immunosuppression, apoptosis plays a pivotal role in the selection of immune cell populations and maintenance of functional immune responses ${ }^{33}$. Cell death in innate and adaptive immune systems benefits the host by downregulating inflammatory response in sepsis, but the extensive loss of immune cells may compromise the ability of the host to eliminate invading pathogens. Immune cell apoptosis in lymphoid tissues and gutassociated lymphoid tissues could cause marked depletion of immune cells, including monocytes and macrophages, DCs, NK cells, and B cells ${ }^{34}$, contributing to immune suppression or secondary infection ${ }^{35}$. The depletion of these immune cells is a universal finding in all age groups and is particularly noteworthy because it occurs during life-threatening infection when clonal expansion of lymphocytes should be occurring. Although circulating lymphocytes undergo significant apoptosis, no apparent apoptosis in the heart, kidneys, lungs, and other substantive organs occurs during the progression of sepsis ${ }^{36}$. Sepsis-induced apoptosis of immune cells could undermine host immunity through anergy, latent infection reactivation, and susceptibility to secondary infections ${ }^{37}$. Importantly, the magnitude of lymphocyte apoptosis is possibly valuable for determining the severity of sepsis. However, the activity of immune cells differs under diverse apoptotic signals during sepsis. Cellular death through apoptosis directly leads to microvascular dysfunction and organ failure during sepsis, with apoptotic immune cells contributing to secondary infection or immune suppression.

\section{Mechanisms and consequences of apoptosis in sepsis}

Although immune cell depletion is a crucial event in the pathology of sepsis-induced immunosuppression, the mechanisms responsible for this are not fully under$\operatorname{stood}^{38}$. One theory is that sepsis could affect apoptosis- 
induced decrease in the number of DCs, which are the most potent antigen-presenting cells (APCs). This then leads to impaired innate and adaptive immune response ${ }^{25}$. In addition, the profound decrease in the number of some critical cells could influence adaptive immune responses between the innate and adaptive systems. The other theory is that some factors, including steroids, cytokines (tumor necrosis factor [TNF]- $\alpha$, high mobility group box1 protein, FasL, and heat shock protein), could regulate apoptosis by directly modulating the activities of caspase8 in the death-induced signaling complex or by changing the levels of death and survival factors that control the Fas apoptotic pathway. Conversely, the release of antiinflammatory cytokines, such as interleukin (IL)-10 and transforming growth factor beta, could accelerate apoptosis.

This process ultimately leads to major consequences. First, with respect to immune response, excessive apoptosis causes massive loss of immune cells. For example, the depletion of macrophages and NK cells impairs microorganism clearance ${ }^{39,40}$, which leads to protracted inflammatory responses. The second major consequence is that uncontrolled apoptosis of immune cells results in immunological tolerance with anti-inflammatory properties $^{41}$. During apoptosis, the release of pro-inflammatory cytokines is inhibited, but the secretion of antiinflammatory factors is activated, indicating a shift from $\mathrm{T}$ helper type 1 (Th1) to Th2 cytokine production ${ }^{25,42}$. The sepsis-induced functional and quantitative changes in immune cells result in lymphopenia, with progression of immune paralysis.

\section{Apoptosis-induced lymphopenia during sepsis}

Sepsis could affect the function of virtually all types of immune cells. In the following section, we will discuss these various immunosuppressive effects on the different cells of the innate and adaptive immune systems.

\section{Neutrophils}

Neutrophils are produced in the bone marrow (BM) and released into the circulation as the most prevalent and integral innate cell population. They are fundamental components of innate immunity and are essential for microbial eradication and for sepsis survival ${ }^{43}$. Neutrophils are the most abundant leukocyte in systemic circulation. They are also present in small amounts in the spleen, liver, and lung ${ }^{44,45}$ apart from the BM, and thus they are critical for early immune response ${ }^{46,47}$. In addition, neutrophils may function as APCs and mediate between innate and adaptive responses in various pathological infections ${ }^{48}$.

In physiological conditions, neutrophils are constitutively pro-apoptotic ${ }^{49}$ and are short-lived granulocytes that undergo energy- and caspase-dependent apoptosis within $24 \mathrm{~h}^{46}$. However, in the early stage of sepsis, the level of neutrophils increase rapidly owing to delayed neutrophil apoptosis ${ }^{25}$, as evidenced by the high neutrophil count observed in animals and sepsis patients only during the first $24 \mathrm{~h}$ of sepsis initiation ${ }^{50}$. This then leads to persistent neutrophil dysfunction, compounded by the release of immature neutrophils from the BM that culminates in neutrophil deficits in oxidative burst ${ }^{51}$, cell migration ${ }^{52,53}$, complement activation, and bacterial clearance $^{54}$, all of which contribute to immune dysfunction and persistent inflammation (Fig. 3). In addition, immature neutrophils are produced and released from the $\mathrm{BM}$, and their circulation aggravates the delayed apopto$\mathrm{sis}^{25}$. Thus the inhibition of neutrophil apoptosis in sepsis could be harmful to host immunity, and neutrophil infiltration into tissues could damage organ function ${ }^{23,55}$. For example, neutrophil infiltration in the lungs is a pathological hallmark of sepsis-induced acute lung injury or acute respiratory distress syndrome ${ }^{56}$. Increased circulating neutrophils result in a dysregulated immune response by releasing cytokines and reactive oxygen species at sites distal to the infectious focus, leading to multiple organ failure (Fig. 4). However, accelerated apoptosis resulted in inflammation resolution in several preclinical models of injury ${ }^{57,58}$.

Various mechanisms governing neutrophil apoptosis have been implicated in sepsis. Intravenous lipopolysaccharide or endotoxin could increase the levels of various gene transcripts in neutrophils, which result in the suppression of neutrophil apoptosis ${ }^{59}$. The delayed apoptosis of neutrophils is associated with disease severity $^{60}$, whereas increased apoptosis is beneficial for fighting infection in hemorrhagic shock ${ }^{61}$. Meanwhile, delayed neutrophil apoptosis but accelerated apoptosis of other immune cells might impair host immune system by increasing the dephosphorylation of epithelial cell caspase- $8^{62}$. Although delayed neutrophil apoptosis results in increased neutrophil counts, some functional deficit in neutrophils are evident during the early and late time points in sepsis patients. Further, some functions decline with protracted sepsis ${ }^{63}$. More interestingly, neutrophil deficiency hastens the development of nosocomial and secondary infections ${ }^{64}$, which is probably due to impaired bacterial clearance and altered pulmonary cytokine response ${ }^{65}$. Currently, neutrophil apoptosisinduced lymphopenia is given more attention for its involvement in the development of secondary infection and as a potential predictor of mortality at 1 year after sepsis $^{66}$. One potential mechanism by which apoptosisinduced lymphopenia occurs is that some neutrophil subsets during sepsis could secrete excessive amounts of IL-10, which restrains the proliferation of T lymphocyte ${ }^{67}$. Another mechanism is that complex interactions between the neutrophils and complement system could also cause 


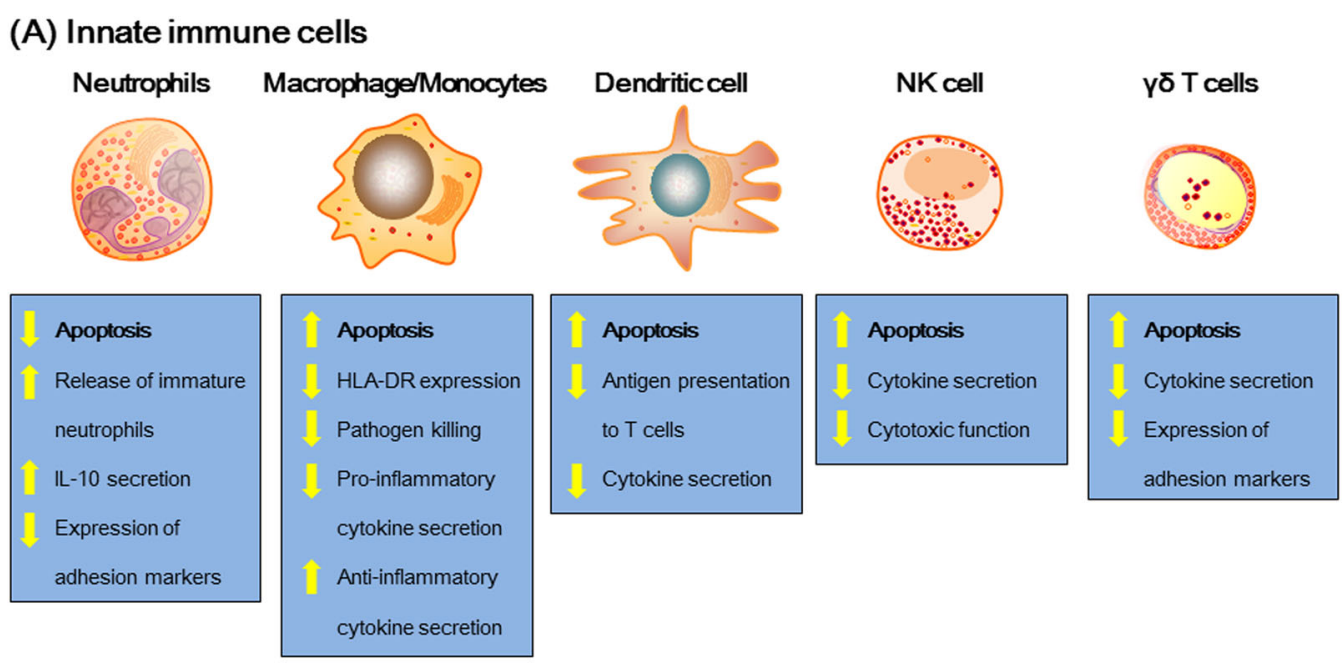

(B) Adaptive immune cells
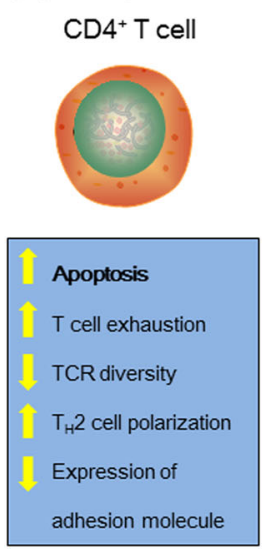

\section{B cell}
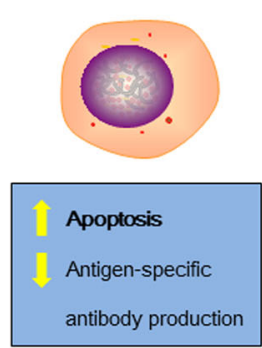

Treg cell
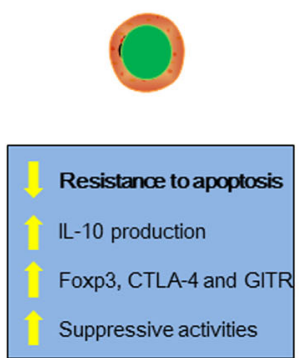

Fig. 3 Sepsis alters innate and adaptive immune cells. Sepsis-induced immune paralysis is characterized by immunological defects that impair host immunity. Lymphoid cell loss, often resulting in the diminished capacity to fight and eliminate pathogens, is a primary feature of immune suppression during sepsis. Altered immune cell function induced by uncontrolled apoptosis is a major cause of profound immunosuppression. Lymphocyte apoptosis, including that of innate immune cells and adaptive immune cells, is associated with a higher risk of secondary infections and poor outcome in various diseases. As shown here, sepsis rapidly triggers profound apoptosis in macrophages/monocytes, dendritic cells, NK cells, $\gamma \delta$ $\mathrm{T}$ cells, CD4 ${ }^{+} \mathrm{T}$ cells, and B cells. However, apoptosis of neutrophils is delayed, and Treg cells are more resistant to sepsis-induced apoptosis. Immune cell depletion due to apoptosis is the primary mechanism of sepsis-induced immune suppression

complement-induced innate immune damage during sepsis $^{68}$. In addition, von Gunten et al. reported that the apoptosis response of neutrophils to a death stimulus (Siglec-9 cross-linking) varies significantly between patients and at different stages of septic shock ${ }^{69}$. The feasibility of neutrophil function and immature neutrophil count as predictors of sepsis has also been evaluated based on the delayed neutrophil apoptosis observed in septic animals and patients ${ }^{70}$.

\section{Monocytes and macrophages}

The impact of sepsis on monocyte subpopulations has been extensively studied. The most notable change during sepsis is that the impairment of bold monocytes from the patients initiates "endotoxin tolerance" and leads to poor outcome. Monocytes and macrophages are major components of the innate immune system and play pivotal roles in orchestrating host immune response during sepsis $^{71}$. At the early phase of sepsis, two different lymphocytes secrete an increased level of pro-inflammatory factors and chemokines, which aggravate the inflammatory response $\mathrm{e}^{72,73}$ and could contribute to increased mortality rate ${ }^{74}$. As sepsis progresses, the excessive apoptosis of monocytes and macrophages could result in immunosuppression and the higher risk of secondary infection or mortality ${ }^{22,75}$. Furthermore, monocyte and macrophage dysfunction leads to decreased release of proinflammatory cytokines, such as TNF- $\alpha$, IL- $1 \beta$, IL- 6 , and IL-12, whereas the release of anti-inflammatory mediators, such as IL-1 receptor antagonist (IL-1ra) and IL-10, 

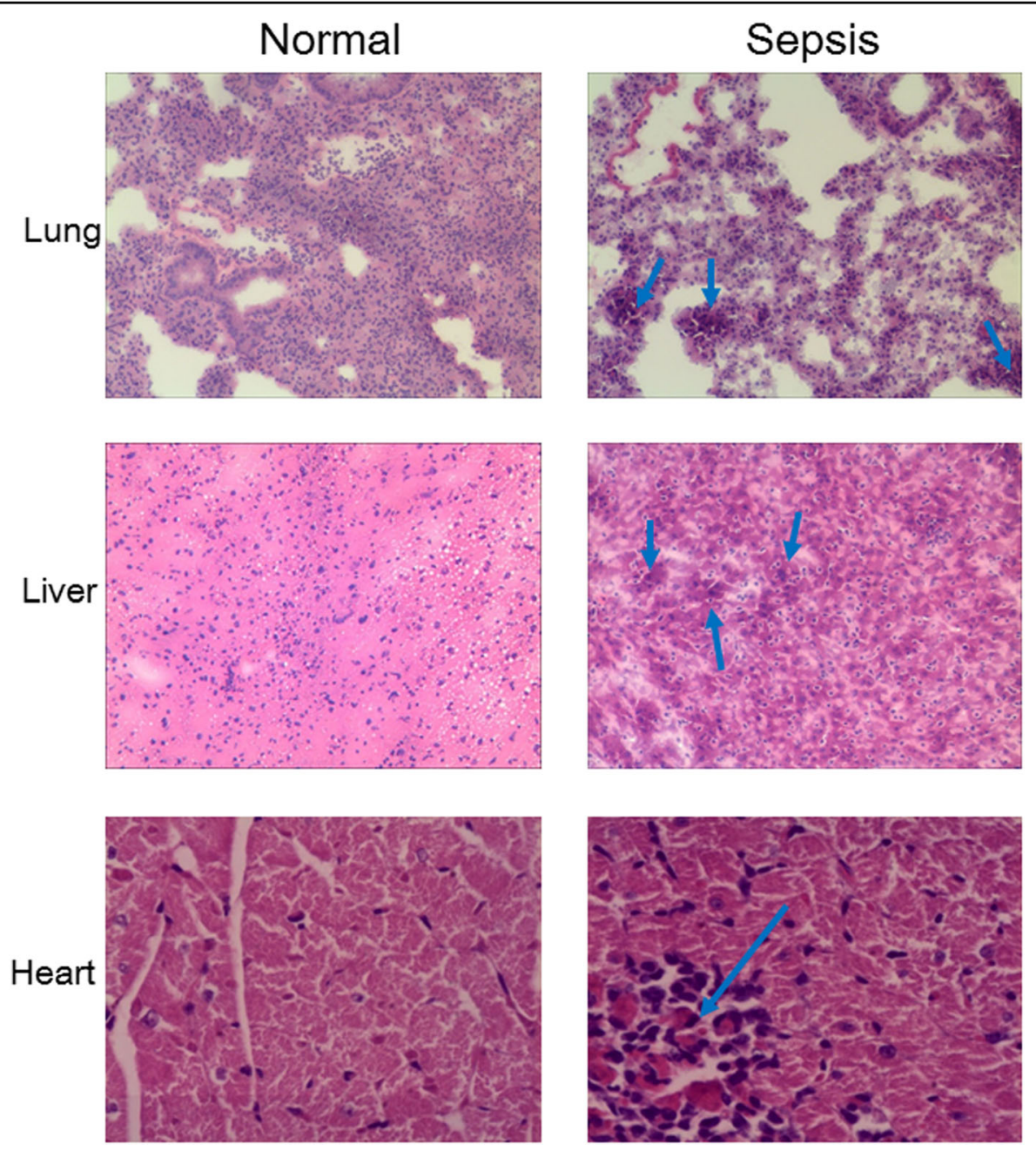

Fig. 4 Sepsis-induced delayed apoptosis and recruitment of neutrophils into tissues lead to multiple organ dysfunction syndrome. The apoptosis of neutrophils is delayed during the first $24 \mathrm{~h}$ after the initiation of sepsis. Then neutrophils are recruited and infiltrate into tissues, aggravating the ongoing neutrophil dysfunction with persistent immune dysfunction and inflammation persistence. Neutrophil infiltration in the lungs is a pathological hallmark of sepsis-induced acute lung injury or acute respiratory distress syndrome as well as of organ dysfunction in the liver and heart. Representative histological changes in tissues are shown in hematoxylin and eosin-stained samples (original magnification $\times 400$ ). Arrows denote the recruitment and infiltration of neutrophils into tissues

is neither impaired nor enhanced (Fig. 3) ${ }^{76-78}$. These changes indicate that intracellular signaling has shifted from production of pro-inflammatory cytokines toward anti-inflammatory mediators associated with nosocomial infections and increased mortality ${ }^{14}$.

Aside from accelerated apoptosis during sepsis, functional defects in monocytes also contribute to the pathophysiology of sepsis-induced immunosuppression, which is characterized by suppressed mononuclear cell HLA-DR expression in monocytes ${ }^{79}$. The decreased level of monocyte HLA-DR could be considered as a marker of monocyte anergy ${ }^{80}$, as it impairs the function of monocytes $^{81}$ and decreases lymphocyte proliferation in response to invading pathogens ${ }^{82}$. Notably, HLA-DR expression is a reliable predictor for the development of nosocomial infections and mortality during sepsis ${ }^{83-86}$, and immunotherapies targeting monocyte function in patients with sepsis are being developed ${ }^{87,88}$.

Macrophages are essential in maintaining and activating host inflammatory responses ${ }^{89}$. Traditionally, macrophages perform two most well-known polarizations: M1 (i.e., expression of inflammatory cytokines) and M2 (i.e., expression of factors that resolve or suppress inflammatory responses) ${ }^{90}$. Macrophage phagocytosis leads to an imbalance of pro- and anti-inflammatory cytokines, resulting in polarization of macrophages to an M2 phenotype. This is characterized by predominant release of anti-inflammatory cytokines, such as IL-10 and IL-1ra, and decrease of pro-inflammatory cytokines ${ }^{91}$. Collectively, sepsis-induced extensive depletion of macrophages 
could seriously impair host antimicrobial defenses, but anti-apoptotic therapies targeting macrophages through anti-apoptotic proteins, such as modulation of $\mathrm{Bcl}-2$ family members, could effectively ameliorate the host response and decrease sepsis-induced morbidity and mortality ${ }^{92}$.

\section{Dendritic cells}

DCs arise from BM progenitors and seed the peripheral tissues as immature cells. They are the most potent APCs and play an essential role in pathogen recognition, regulation of immune response, and inflammation ${ }^{93,94}$ by linking the innate and adaptive immunity ${ }^{95,96}$. DCs are classified into two types: conventional DCs (cDCs) and plasmacytoid DCs $(\mathrm{pDCs})^{97}$. cDCs, such as monocytes, can also secrete IL-12, while pDCs are similar to plasma cells and secrete large amounts of interferon (IFN)- $\alpha$. DCs, including plasmacytoid and myeloid DCs, are markedly reduced in the spleen and circulation during sepsis $^{98}$. Notably, the loss of DCs seems associated with worse clinical outcomes in sepsis including death and nosocomial infections ${ }^{99-101}$. For example, the number of DCs was markedly reduced in both the spleen and mesenteric nodes at $12 \mathrm{~h}$ in septic models created via cecal ligation puncture ${ }^{102}$. Although the excessive depletion of DCs could induce accelerated differentiation of monocytes into DCs ${ }^{103,104}$, it does not compensate for the excessive depletion of DCs, and the number of DCs continue to decrease along with impaired functional capability ${ }^{105}$. The levels of surface molecules associated with the function of DCs, including CD40 and CD86 as well as major histocompatibility complex (MHC)-DR, markedly decrease, but the release of IL-10 tends to increase (Fig. 3) ${ }^{96,106}$. These changes lead surviving DCs to transform to tolerogenic DCs, which are DCs that are unable to induce an allogeneic $\mathrm{T}$ cell activation but lead to either $\mathrm{T}$ cell anergy or Treg cell proliferation ${ }^{107}$. Under this condition, DCs with immunosuppressive properties that undermine immune responses are lost, thus leading to failure of activation of the immune response of effector $\mathrm{T}$ cells and ultimately results to an immunosuppressive state and organ injury ${ }^{105,108}$. Thus the profound depletion of DCs has been considered as an early predictive biomarker for the outcome of sepsis ${ }^{109}$.

There are several mechanisms involved in the induction of DC apoptosis, including abnormal activation of the nuclear factor of activated T cells (NFAT) and an influx of extracellular $\mathrm{Ca}^{2+}$ and calcineurin-dependent nuclear NFAT translocation ${ }^{110}$. Further investigation found that DCs profoundly affected the systemic impact of severe sepsis through Toll-like receptor (TLR) signaling pathways by increasing the expression of MHC class II antigen and costimulatory molecules $\mathrm{CD} 80$ and $\mathrm{CD} 8^{63}$. Multiple reports have shown that blocking sepsis-induced DC apoptosis or augmenting DC function could enhance sepsis survival ${ }^{11-113}$, indicating that preventing DC apoptosis could be a promising treatment strategy for sepsis.

\section{NK cells}

NK cells have been heavily studied in sepsis due to their low number in the circulation but high numbers in tissues $^{114}$; thus their contribution to the pathophysiology of sepsis remains unclear ${ }^{115}$. Only $5-15 \%$ of blood lymphocytes do not express specific receptors ${ }^{116}$. Traditionally, NK cells are recognized as immune regulators and are divided into different subpopulations based on CD16 and CD56 expression ${ }^{117}$. In humans, NK cells are characterized as $\mathrm{CD}^{-} \mathrm{NKp} 46^{+} \mathrm{CD}^{-} 6^{+}$cells $^{118}$. Under normal conditions, NK cells can induce a rapid, non-specific innate immune response against intracellular bacteria, pyogenic bacteria, fungi, protozoa ${ }^{119}$, and viral infections $^{120,121}$ through direct cytotoxicity against virusinfected cells and early production of cytokines that can inhibit viral replication. Further, NK cells are the major producers of IFN $-\gamma^{122}$. In addition, NK cells play an important role in initiating host defense and coordinating innate and adaptive immune responses during sepsis ${ }^{123}$.

The most important change is that the accelerated apoptosis of NK cells leads to the decreased number of circulating NK cells ${ }^{124,125}$ that lasts for several weeks during sepsis ${ }^{126}$. Both CD56 ${ }^{\text {hi }}$ and CD56 ${ }^{\text {lo }}$ NK cell subpopulations are altered, and this is associated with increased mortality in patients with sepsis ${ }^{127,128}$. More importantly, the cytotoxic function of NK cell is decreased ${ }^{40}$, which contributes to sepsis-induced immunosuppression (Fig. 3). Furthermore, the decreased level of IFN- $\gamma$ caused by excessive apoptosis of NK cells increases the risk of secondary infection ${ }^{129}$.

The loss of NK cells directly affects the immune responses in sepsis patients and thus may be a potential target for therapeutic intervention ${ }^{130,131}$. For example, PD-1/programmed cell death ligand-1 (PD-L1) blockadebased immunotherapy can be used during sepsisassociated immunosuppression that develops due to the loss of protective function of NK cells ${ }^{132,133}$. Thus NK cell-based immunotherapy and immunomodulatory molecules specifically targeting $\mathrm{NK}$ cells and their immunometabolism may open a future avenue to target sepsis $^{134}$.

\section{Gamma delta $(\gamma \delta)$ T cells}

$\gamma \delta \mathrm{T}$ cells are a distinct lymphocyte population with a unique and expansive function. They play a pivotal role in protecting tissues against bacterial, viral, and parasitic pathogen damage ${ }^{135} \cdot \gamma \delta$ T cells comprise a small subset of $\mathrm{T}$ cells that possess a distinct $\mathrm{T}$ cell receptor (TCR) on their cell surface, that is, a TCR comprised of one $\gamma$ chain 
and one $\delta$ chain. These cells exhibit features of both innate and adaptive immunity and play an indispensable role in host defense, immune surveillance, and homeostasis $^{136} \cdot \gamma \delta \mathrm{T}$ cells contribute to both innate and acquired immune responses during sepsis, with IFN- $\gamma$, IL17, and other chemokines being released after $\gamma \delta \mathrm{T}$ cell activation.

In sepsis patients, $\gamma \delta \mathrm{T}$ cells are activated with increased surface expression of CD69 and HLA-DR, but the number of circulating $\gamma \delta \mathrm{T}$ cells is significantly lower than that of healthy subjects ${ }^{137,138}$, and the reductions correlate with the severity of illness and highest mortality rates ${ }^{139,140}$. This is probably because the apoptosis-induced loss of $\gamma \delta$ $\mathrm{T}$ cells in the intestinal mucosa results in higher susceptibility to secondary infections as pathogens invade the circulation or peritoneal cavity (Fig. 3$)^{13}$. The number of $\gamma \delta \mathrm{T}$ cells in the peripheral circulation decreases by as much as $80 \%{ }^{141}$. Liao et al. found that changes in the function-related markers of $\gamma \delta \mathrm{T}$ cells in the blood of sepsis patients and impaired IFN- $\gamma$ expression by $\gamma \delta$ $\mathrm{T}$ cells after antigen stimulation are associated with mortality in sepsis patients ${ }^{142}$. Furthermore, $\gamma \delta \mathrm{T}$ cell deficiency impairs the immune defenses and increases the mortality risk in sepsis ${ }^{143}$. Expansion of the $\gamma \delta \mathrm{T}$ cell population increased the resistance of immunodeficient mice to bacterial infection ${ }^{144}$. Collectively, these findings show that preventing $\gamma \delta \mathrm{T}$ cell apoptosis could attenuate inflammatory responses ${ }^{145}$, providing new insight in the understanding of the functions of $\gamma \delta \mathrm{T}$ cells in sepsis.

\section{$\mathrm{CD}^{+} \mathrm{T}$ cells and associated subpopulations}

$\mathrm{T}$ lymphocytes are key elements in all adaptive immune responses. $\mathrm{CD}^{+}{ }^{+} \mathrm{T}$ cells are among the most important peripheral lymphocyte subsets in terms of modulating successful immune responses, influencing innate and adaptive immune cells through cytokine production, and cell-to-cell interaction ${ }^{146,147}$. When presented with peptide antigens, mature $\mathrm{CD} 4^{+} \mathrm{T}$ cells become activated and rapidly divide into several subsets that facilitate various immune responses by differing cytokine generation and secretion upon activation ${ }^{148}$. Among these cell subsets, Th1, Th2, and Th17 cells are major representatives of Th cells and are further explored here.

Apoptosis of $\mathrm{T}$ lymphocytes is critical in the pathophysiology of sepsis, and $\mathrm{CD} 4^{+} \mathrm{T}$ cells could directly mediate the host response to sepsis ${ }^{149}$. The number of $\mathrm{T}$ lymphocytes undergoing apoptosis is significantly reduced during sepsis and is even higher in non-survivors than survivors $^{150}$. One of the most notable $\mathrm{T}$ cell defects induced by sepsis is the development of apoptosis, which destroys the $\mathrm{CD}^{+} \mathrm{T}$ cell population (Fig. 3) ${ }^{151,152}$. Uncontrolled apoptosis of $\mathrm{CD} 4^{+} \mathrm{T}$ cells causes marked lymphocytopenia, which is particularly serious because clonal expansions are critical to overcome potentially lethal infections. Patients who died of sepsis were found to have a much greater magnitude of $\mathrm{CD} 4^{+} \mathrm{T}$ cell apoptosis than survivors ${ }^{23}$.

Several treatments to prevent immunosuppression have targeted the apoptosis of $\mathrm{CD} 4^{+} \mathrm{T}$ cells in animal mod$\mathrm{els}^{153,154}$. Of note, IL-7 has emerged as a promising therapeutic agent because it has been found to be essential in preventing $\mathrm{T}$ cell depletion ${ }^{155}$. IL-7 administration has been shown to effectively improve $\mathrm{T}$ cell viability and trafficking and release of IFN- $\gamma$ and restore the delayedtype hypersensitivity response to recall antigens ${ }^{156}$, which improves survival in sepsis. Another promising approach in reversing immunosuppression in sepsis involves blockade of the co-inhibitory molecules PD-1 and PD-L1. PD-1 blockade has been reported to increase the release of IFN- $\gamma$ and prevent $\mathrm{T}$ cell apoptosis in patients with active infections ${ }^{157}$. However, the mechanisms inhibiting $\mathrm{T}$ cell apoptosis during sepsis are complex and yet to be completely understood ${ }^{158}$.

Not only the number of $\mathrm{CD} 4^{+} \mathrm{T}$ cell populations but also the function of the remaining lymphocytes is reduced during sepsis. Sepsis leads to uncontrolled apoptosisinduced depletion of $\mathrm{CD}^{+}{ }^{+} \mathrm{T}$ cells, and some remaining cells are rendered dysfunctional or exhausted due to the prolonged exposure to excessive pro- and antiinflammatory cytokines. $\mathrm{CD}^{+} \mathrm{T}$ cell exhaustion has been typified by $\mathrm{T}$ cells that have severely impaired effector functions and has been found in patients with sepsis. The prolonged duration of sepsis is characterized by high antigen load and elevated pro- and antiinflammatory cytokines, which is conducive for $\mathrm{T}$ cell exhaustion ${ }^{159}$. The association between $\mathrm{T}$ cell exhaustion and increased mortality in sepsis is due to immune paralysis and secondary nosocomial infections ${ }^{160,161}$. Multiple independent studies have reported that blockade of the PD-1/PD-L1 pathway could attenuate $T$ cell exhaustion, increase IFN $-\gamma$ production, prevent apoptosis, and improve survival in various pathologic models of sepsis ${ }^{162-164}$. Collectively, these findings indicate that $\mathrm{T}$ cell exhaustion is also a major etiology of immune dysfunction in sepsis and that reversal of putative $T$ cell exhaustion is a promising modality in the treatment of sepsis.

\section{B cells}

B cells play an important role in both adaptive and innate immune response ${ }^{165}$. Under physiological circumstances, activated effector B cells could differentiate into plasma cells or memory B cells and drive the humoral immune response and act as APCs to activate effector $\mathrm{T}$ cells ${ }^{166}$. B cell function is relegated to the production of antibodies (Abs) and the development of memory plasma $\mathrm{B}$ cells ${ }^{165}$. Multiple studies have documented that impaired B cell function ${ }^{167,168}$, along with the production 
Table 1 Immune modulators and proposed benefits for sepsis-induced apoptosis therapy

\begin{tabular}{|c|c|c|}
\hline Immune modulator & Effects & Reference \\
\hline G-CSF & Improve neutrophils and monocyte production and release & 194 \\
\hline GM-CSF & Activate and induce production of neutrophils and monocytes or macrophages and reduce cell death & 195,196 \\
\hline IFN- $\gamma$ & Increase monocyte expression of HLA-DR, increase numbers of IL-17 producing $\mathrm{CD}^{+}{ }^{+} \mathrm{T}$ cells & 197,198 \\
\hline PD-1/PD-L1 & $\begin{array}{l}\text { Anti-apoptotic effects to prevent loss of protective function of NK cells } \\
\text { Prevent lymphocyte apoptosis and reverse monocyte dysfunction }\end{array}$ & $132,133,199,200$ \\
\hline IL-7 & $\begin{array}{l}\text { Blockade of sepsis-induced apoptosis depletion, increase production of } \mathrm{CD}^{+}{ }^{+} \mathrm{T} \text { and } \mathrm{CD} 8 \mathrm{~T} \text { cells } \\
\text { Enhance trafficking of } \mathrm{T} \text { cells to sites of infection }\end{array}$ & $1,156,201$ \\
\hline IL-15 & Restrain sepsis-induced apoptosis of CD8 T cells, NK cells, and DCs & 130 \\
\hline Tim-2-specific antibody & Decrease lymphocyte apoptosis and reverse the macrophage function & 202,203 \\
\hline Ulinastatin & Increase apoptotic rate of Treg cells and reduce the percentage through NF-KB pathway, ameliorate mortality & 188 \\
\hline CTLA-4-specific antibody & Improve overall sepsis-induced lymphocyte apoptosis and survival of secondary fungal infections & 163,204 \\
\hline
\end{tabular}

G-CSF granulocyte colony-stimulating factor, GM-CSF granulocyte-macrophage colony-stimulating factor, IFN- $\gamma$ interferon gamma, $P D-1$ programmed cell death-1, IL interleukin, CTLA-4 cytotoxic T lymphocyte antigen-4

of IL-10 ${ }^{169,170}$, the presentation of microorganism antigens to $\mathrm{T}$ lymphocytes ${ }^{171}$, and interaction of several bacterial products with $\mathrm{B}$ cells ${ }^{165,172}$, weakens immunity during sepsis. The relative proportion of B cell subsets is decreased on admission day in critically ill patients with sepsis, indicating that the apoptosis of $\mathrm{B}$ cells was induced $^{173,174}$. In addition, endotoxemia causes a transient depletion of memory B cells and regulatory B cells from the circulation, but the functional capacity of B cells to produce IL-10 is maintained (Fig. 3$)^{175}$.

Excessive apoptosis of B cells in sepsis likely involves multiple pathogen-sensing receptors and redundant signaling pathways. For example, Octavia et al. found that myeloid differentiation primary response gene 88 (MyD88) was effective in blocking the apoptosis of B cells, and MyD88 deficiency could markedly decrease B cells apoptosis, but the mortality rate significantly increased ${ }^{176}$. However, administration of Tubastatin A, a selective inhibitor of histone deacetylase 6 , restored the percentage of B lymphocytes and significantly increased the percentages of innate immune cells and macrophages ${ }^{177}$. Therefore, therapies targeted at reversing B cell depletion should be actively investigated.

\section{Treg cells}

Treg cells are a component of adaptive immunity that suppress responses of other effector $\mathrm{T}$ cell subsets, helping to maintain tolerance to self-antigens and suppression of autoimmune disease ${ }^{178}$. Treg cells are involved in the maintenance of peripheral tolerance and control of the immune processes ${ }^{179,180}$. Furthermore, Treg cells play a key role in controlling inflammation in many infectious diseases, including sepsis ${ }^{180,181}$. In sepsis and critical illness, Treg cells are detrimental to the proliferation and functional activity of effector $\mathrm{T}$ cells and other immune cells; for example, Treg cells inhibit both monocyte and neutrophil function ${ }^{82}$.

The number of circulating Treg cells increase in septic shock, particularly in the early stages after initiation. Further, although this increase was observed immediately after the onset of sepsis, it persisted only in those who subsequently died ${ }^{182}$. Further study revealed that the increase in Treg cells is caused by the loss of effector $\mathrm{T}$ cells rather than an absolute increase in Treg cells ${ }^{183}$. The involvement of these cells in long-term sepsisinduced immune dysfunction ${ }^{184}$ may be attributed to inhibition of monocyte function through a pro-apoptotic mechanism involving the Fas/FasL pathway ${ }^{82}$. Treg cells are less vulnerable to sepsis-induced apoptosis; therefore, the percentage of Treg cells increases in patients with sepsis ${ }^{185,186}$. Cell apoptosis is a continuous state, but Treg cells are more resistant to sepsis-induced apoptosis than other $\mathrm{T}$ cell subpopulations ${ }^{1,187}$, thus the increased ratio of Treg cells during the early period after sepsis. Increased Treg cell population would prevent recovery of the immune system from excessive immune responses. Importantly, these resistant effects are possibly due to TLR4 deficiency and associated NF- $\mathrm{kB}$ signal pathways ${ }^{188}$.

The higher number of Treg cells in sepsis patients impairs immunity and contributes to secondary infections and mortality by acting both on innate and adaptive immune cells (Fig. 3). However, the role of Treg cells in septic injury is yet to be clarified. Although prevention of Treg cell apoptosis inhibited immune responses or decreased survival in animal models of sepsis, the removal of Treg cells via anti-CD25 monoclonal Ab administration did not improve survival in animal model ${ }^{189}$. This may be because not only Treg cells but also other $\mathrm{T}$ cell 
subpopulations are depleted. In conclusion, Treg cells are more resistant to apoptosis in sepsis, thus potentially serving as targets for immune modulation.

\section{Clinical perspectives}

Given the profound immunosuppression induced by depletion of immune cells that occurs during sepsis, the ability to sequentially follow the uncontrolled lymphocyte apoptosis as a means to evaluate the efficacy of immuneadjuvant therapies provides promising novel therapeutic opportunities ${ }^{190}$. The potential of preventing lymphocyte apoptosis as a treatment strategy in sepsis has been supported by many animal model studies. The first study to report that prevention of apoptosis improved the survival in sepsis showed that $\mathrm{Bcl}-2$ overexpression is more resistant to sepsis-induced apoptosis ${ }^{191}$. Furthermore, an increasing number of immunoadjuvant therapies to prevent sepsis-induced immune paralysis have been identified as apoptosis dependent. IL-7 and anti-PD-L1 have been found to have potent effects to prevent lymphocyte apoptosis. IL-7 administration is an attractive therapy in sepsis, because it blocks sepsis-induced apoptosis of immune effector cells and increases IFN- $\gamma$, a cytokine that is critical for an effective host response against invading pathogens. This presents a potential novel strategy in the treatment of patients with sepsis by restoring adaptive immunity. Such immune-based therapy should be broadly protective against numerous bacterial and fungal pathogens ${ }^{192}$. More specifically, other agents, such as granulocyte colony-stimulating factor, granulocyte-macrophage colony-stimulating factor, IFN- $\gamma$, IL-15, anti-PD-1/PD-L1, and anti- $\mathrm{B}$ and $\mathrm{T}$ lymphocyte attenuator will target the immunosuppressed state in critically ill patients (Table 1$)^{193}$. Therefore, development of a non-invasive imaging modality to detect and serially follow apoptotic cell death could be helpful in evaluating the efficacy of immunoadjuvant therapies in sepsis patients. This provides a bright prospect of autophagic modulation in clinical application.

\section{Conclusion}

Impaired apoptosis aggravates sepsis-induced immunosuppression in both innate and adaptive immune systems. Thus manipulating apoptosis could be a new therapeutic approach in sepsis. Further, exploring potential therapeutic targets related to apoptosis will be valuable in reversing sepsis-induced immunosuppression.

\section{Acknowledgements}

We thank professor Dan Lyu of the Department of Anesthesiology of the University of lowa for guidance in study presentation. This work was supported by grants from the National Natural Science Foundation of China (Grant No. 81902007 to C.C., No. 81871593 to Y.C.) and the Natural Science Foundation of Tianjin (Grant No. 19JCQNJC10000 to C.C., No. 17JCQNJC12400 to M.Y.).

\section{Authors' contributions}

C.C. conducted the literature review and drafted the manuscript. M.Y. critically revised the manuscript. Y.C. designed the study and helped draft the manuscript.

\section{Author details}

${ }^{1}$ Tianjin Medical University General Hospital, Tianjin, China. ${ }^{2}$ Tianjin Medical University, Tianjin, China. ${ }^{3}$ Department of Internal Medicine, The University of lowa Carver College of Medicine, lowa City, IA, USA

\section{Data availability}

The dataset used for this study is available from the corresponding author on reasonable request.

\section{Conflict of interest}

The authors declare that they have no conflict of interest.

\section{Publisher's note}

Springer Nature remains neutral with regard to jurisdictional claims in published maps and institutional affiliations.

Received: 14 July 2019 Revised: 28 August 2019 Accepted: 2 September 2019

Published online: 14 October 2019

\section{References}

1. Hotchkiss, R. S., Monneret, G. \& Payen, D. Immunosuppression in sepsis: a novel understanding of the disorder and a new therapeutic approach. Lancet Infect. Dis. 13, 260-268 (2013).

2. Marshall, J. C. Why have clinical trials in sepsis failed? Trends Mol. Med. 20, 195-203 (2014).

3. Fink, M. P. \& Warren, H. S. Strategies to improve drug development for sepsis. Nat. Rev. Drug Discov. 13, 741-758 (2014).

4. Rhodes, A. et al. Surviving Sepsis Campaign: International Guidelines for Management of Sepsis and Septic Shock: 2016. Intensive Care Med. 43, 304-377 (2017).

5. Marik, P. E. et al. Fluid administration in severe sepsis and septic shock, patterns and outcomes: an analysis of a large national database. Intensive Care Med. 43, 625-632 (2017).

6. Dellinger, R. P. \& Vincent, J. L. The Surviving Sepsis Campaign sepsis change bundles and clinical practice. Crit. Care 9, 653-654 (2005).

7. Suarez De La Rica, A., Gilsanz, F. \& Maseda, E. Epidemiologic trends of sepsis in western countries. Ann. Transl. Med. 4, 325 (2016).

8. Cohen, J. et al. Sepsis: a roadmap for future research. Lancet Infect. Dis. 15, 581-614 (2015).

9. Fleischmann, C. et al. Assessment of global incidence and mortality of hospital-treated sepsis. current estimates and limitations. Am. J. Respir. Crit. Care Med. 193, 259-272 (2016).

10. van der Poll, T. et al. The immunopathology of sepsis and potential therapeutic targets. Nat. Rev. Immunol. 17, 407-420 (2017).

11. Langley, R. J. et al. An integrated clinico-metabolomic model improves prediction of death in sepsis. Sci. Transl. Med. 5, 195ra195 (2017).

12. Hall, M. J. et al. Inpatient care for septicemia or sepsis: a challenge for patients and hospitals. NCHS Data Brief. 62, 1-8 (2011).

13. Hotchkiss, R. S., Monneret, G. \& Payen, D. Sepsis-induced immunosuppression: from cellular dysfunctions to immunotherapy. Nat. Rev. Immunol. 13, 862-874 (2013).

14. Delano, M. J. \& Ward, P. A. Sepsis-induced immune dysfunction: can immune therapies reduce mortality? J. Clin. Invest. 126, 23-31 (2016).

15. Needham, D. M. et al. Improving long-term outcomes after discharge from intensive care unit: report from a stakeholders' conference. Crit. Care Med. 40, 502-529 (2012).

16. Kaukonen, $\mathrm{K} . \mathrm{M}$. et al. Systemic inflammatory response syndrome criteria in defining severe sepsis. N. Engl. J. Med. 372, 1629-1638 (2015).

17. Vincent, J.-L. et al. Sepsis definitions: time for change. Lancet 381, 774-775 (2013). 
18. Singer, M. et al. The Third International Consensus Definitions for Sepsis and Septic Shock (Sepsis-3). JAMA 315, 801-810 (2016).

19. Kahn, J. M. et al. The epidemiology of chronic critical illness in the United States. Crit. Care Med. 43, 282-287 (2015).

20. Hotchkiss, R. S. \& Opal, S. Immunotherapy for sepsis-a new approach against an ancient foe. N. Engl. J. Med. 363, 87-89 (2010).

21. Torgersen, C. et al. Macroscopic postmortem findings in 235 surgical intensive care patients with sepsis. Anesth. Analg. 108, 1841-1847 (2009).

22. Otto, G. P. et al. The late phase of sepsis is characterized by an increased microbiological burden and death rate. Crit. Care 15, R183 (2011).

23. Boomer, J. S. et al. Immunosuppression in patients who die of sepsis and multiple organ failure. JAMA 306, 2594-2605 (2011).

24. Hotchkiss, R. S. et al. Sepsis and septic shock. Nat. Rev. Dis. Prim. 2, 16045 (2016).

25. Hotchkiss, R. S. \& Nicholson, D. W. Apoptosis and caspases regulate death and inflammation in sepsis. Nat. Rev. Immunol. 6, 813-822 (2006).

26. Hotchkiss, R. S., Tinsley, K. W. \& Karl, I. E. Role of apoptotic cell death in sepsis. Scand. J. Infect. Dis. 35, 585-592 (2009).

27. Delano, M. J. \& Ward, P. A. The immune system's role in sepsis progression, resolution, and long-term outcome. Immunol. Rev. 274, 30-353 (2016).

28. Hattori, Y. et al. Insights into sepsis therapeutic design based on the apoptotic death pathway. J. Pharmacol. Sci. 14, 354-365 (2010).

29. Hotchkiss, R. S. \& Crouser, E. Imaging apoptosis in sepsis-a technology we would die for! Crit. Care Med. 43, 2506-2508 (2015).

30. Oberholzer, C. et al. Targeted adenovirus-induced expression of IL-10 decreases thymic apoptosis and improves survival in murine sepsis. Proc. Natl Acad. Sci. USA 98,11503-11508 (2001).

31. Ayala, A. et al. Blockade of apoptosis as a rational therapeutic strategy for the treatment of sepsis. Novartis Found. Symp . 280, 37-49 (2007). Discussion 49-52, 160-164.

32. Cohen, J. J. et al. Apoptosis and programmed cell death in immunity. Annu. Rev. Immunol. 10, 267-293 (1992).

33. Ayala, A. et al. Apoptosis in sepsis: mechanisms, clinical impact and potential therapeutic targets. Curr. Pharm. Des. 14, 1853-1859 (2009).

34. Hotchkiss, R. S. et al. Rapid onset of intestinal epithelial and lymphocyte apoptotic cell death in patients with trauma and shock. Crit. Care Med. 28, 3207-3217 (2000).

35. Zheng, D. et al. Inhibition of microRNA 195 prevents apoptosis and multipleorgan injury in mouse models of sepsis. J. Infect. Dis. 213, 1661-1670 (2016).

36. Benjamim, C. F. et al. Reversal of long-term sepsis-induced immunosuppression by dendritic cells. Blood 105, 3588-3595 (2005).

37. Zeerleder, S. et al. Elevated nucleosome levels in systemic inflammation and sepsis. Crit. Care Med. 31, 1947-1951 (2003).

38. Hotchkiss, R. S. et al. Cell death. N. Engl. J. Med. 361, 1570-1583 (2009).

39. Huber-Lang, M. S. et al. Complement-induced impairment of innate immunity during sepsis. J. Immunol. 169, 3223-31 (2002).

40. Chiche, L. et al. Interferon-gamma production by natural killer cells and cytomegalovirus in critically ill patients. Crit. Care Med. 40, 3162-3169 (2012).

41. Henson, P. M. \& Bratton, D. L. Antiinflammatory effects of apoptotic cells. J. Clin. Invest 123, 2773-2774 (2013).

42. Lerman, Y. V. et al. Sepsis lethality via exacerbated tissue infiltration and TLRinduced cytokine production by neutrophils is integrin alpha3beta1dependent. Blood 124, 3515-3523 (2011).

43. Nathan, C. Neutrophils and immunity: challenges and opportunities. Nat. Rev. Immunol. 6, 173-182 (2006).

44. Kolaczkowska, E. \& Kubes, P. Neutrophil recruitment and function in health and inflammation. Nat. Rev. Immunol. 13, 159-175 (2013).

45. Summers, C. et al. Neutrophil kinetics in health and disease. Trends Immunol. 31, 318-324 (2010).

46. Tamayo, E. et al. Evolution of neutrophil apoptosis in septic shock survivors and nonsurvivors. J. Crit. Care 27, 415 e1-11 (2012).

47. Borregaard, N. Neutrophils, from marrow to microbes. Immunity 33, 657-670 (2010)

48. Davey, M. S. et al. Microbe-specific unconventional T cells induce human neutrophil differentiation into antigen cross-presenting cells. J. Immunol. 193, 3704-3716 (2014).

49. Geering, B. \& Simon, H. U. Peculiarities of cell death mechanisms in neutrophils. Cell Death Differ. 18, 1457-1469 (2011).

50. Taneja, R. et al. Delayed neutrophil apoptosis in sepsis is associated with maintenance of mitochondrial transmembrane potential and reduced caspase-9 activity. Crit. Care Med. 32, 1460-1469 (2004).
51. Delano, M. J. et al. Sepsis induces early alterations in innate immunity that impact mortality to secondary infection. J. Immunol. 186, 195-202 (2013).

52. Eash, K. J. et al. CXCR2 and CXCR4 antagonistically regulate neutrophil trafficking from murine bone marrow. J. Clin. Invest. 120, 2423-2431 (2010).

53. Delano, M. J. et al. Neutrophil mobilization from the bone marrow during polymicrobial sepsis is dependent on CXCL12 signaling. J. Immunol. 187, 911-918 (2011).

54. Grailer, J. J. et al. Persistent neutrophil dysfunction and suppression of acute lung injury in mice following cecal ligation and puncture sepsis. J. Innate Immun. 6, 695-705 (2014).

55. Abraham, E. Neutrophils and acute lung injury. Crit. Care Med. 31(4 Suppl), S195-199 (2003).

56. Grommes, J. \& Soehnlein, O. Contribution of neutrophils to acute lung injury. Mol. Med. 17, 293-307 (2011).

57. Leitch, A. E. et al. Cyclin-dependent kinases 7 and 9 specifically regulate neutrophil transcription and their inhibition drives apoptosis to promote resolution of inflammation. Cell Death Differ. 19, 1950-1961 (2012).

58. Lucas, C. D. et al. Downregulation of Mcl-1 has anti-inflammatory pro-resolution effects and enhances bacterial clearance from the lung. Mucosal Immunol. 7, 857-868 (2014).

59. de Kleijn, S. et al. Transcriptome kinetics of circulating neutrophils during human experimental endotoxemia. PLOS ONE 7, e38255 (2012).

60. Fialkow, L. et al. Neutrophil apoptosis: a marker of disease severity in sepsis and sepsis-induced acute respiratory distress syndrome. Crit. Care 10, R155 (2006).

61. Anne Morrison, C. et al. Increased apoptosis of peripheral blood neutrophils is associated with reduced incidence of infection in trauma patients with hemorrhagic shock. J. Infect. 66, 87-94 (2013).

62. Jia, S. H. \& Parodo, J. et al. Activated neutrophils induce epithelial cell apoptosis through oxidant-dependent tyrosine dephosphorylation of caspase-8. Am. J. Pathol. 184, 1030-1040 (2014).

63. Patera, A. C. et al. Frontline Science: Defects in immune function in patients with sepsis are associated with PD-1 or PD-L1 expression and can be restored by antibodies targeting PD-1 or PD-L1. J. Leukoc. Biol. 100 1239-1254 (2016).

64. Morris, A. C. et al. C5a-mediated neutrophil dysfunction is RhoA-dependent and predicts infection in critically ill patients. Blood 117, 5178-5188 (2011).

65. Robertson, C. M. et al. Neutrophil depletion causes a fatal defect in murine pulmonary Staphylococcus aureus clearance. J. Surg. Res. 150, 278-285 (2008).

66. Drewry, A. M. et al. Persistent lymphopenia after diagnosis of sepsis predicts mortality. Shock 42, 383-391 (2014).

67. Kasten, K. R., Muenzer, J. T. \& Caldwell, C. C. Neutrophils are significant producers of IL-10 during sepsis. Biochem. Biophys. Res. Commun. 393, 28-31 (2010).

68. Liu, L. \& Sun, B. Neutrophil pyroptosis: new perspectives on sepsis. Cell Mol. Life Sci. 76, 2031-2042 (2019).

69. von Gunten, S. et al. Different patterns of Siglec-9-mediated neutrophil death responses in septic. Shock 32, 386-392 (2009).

70. Seok, Y. et al. Delta neutrophil index: a promising diagnostic and prognostic marker for sepsis. Shock 37, 242-246 (2012).

71. Parihar, A., Eubank, T. D. \& Doseff, A. I. Monocytes and macrophages regulate immunity through dynamic networks of survival and cell death. J. Innate Immun. 2, 204-215 (2010).

72. Lauvau, G., Loke, P. \& Hohl, T. M. Monocyte-mediated defense against bacteria, fungi, and parasites. Semin. Immunol. 27, 397-409 (2015).

73. Hamidzadeh, K. et al. Macrophages and the recovery from acute and chronic inflammation. Annu. Rev. Physiol. 79, 567-592 (2017).

74. Molgaard-Nielsen, D., Pasternak, B. \& Hviid, A. Oral fluconazole during pregnancy and risk of birth defects. N. Engl. J. Med. 369, 2061-2062 (2013).

75. Wang, T. S. \& Deng, J. C. Molecular and cellular aspects of sepsis-induced immunosuppression. J. Mol. Med. (Berl.) 86, 495-506 (2008).

76. Biswas, S. K. \& Lopez-Collazo, E. Endotoxin tolerance: new mechanisms, molecules and clinical significance. Trends Immunol. 30, 475-487 (2009).

77. Fumeaux, T. \& Pugin, J. Is the measurement of monocytes HLA-DR expression useful in patients with sepsis? Intensive Care Med 32, 1106-1108 (2008).

78. Sinistro, A. et al. Downregulation of CD40 ligand response in monocytes from sepsis patients. Clin. Vaccin. Immunol. 15, 1851-1858 (2008).

79. Drewry, A. M. et al. Monocyte function and clinical outcomes in febrile and afebrile patients with severe sepsis. Shock 50, 381-387 (2018). 
80. Lukaszewicz, A. C. et al. Monocytic HLA-DR expression in intensive care patients: interest for prognosis and secondary infection prediction. Crit. Care Med. 37, 2746-2752 (2009).

81. Monneret, G. et al. Monitoring immune dysfunctions in the septic patient: a new skin for the old ceremony. Mol. Med. 14, 64-78 (2008).

82. Venet, F. et al. Human CD4+CD25+ regulatory t lymphocytes inhibit lipopolysaccharide-induced monocyte survival through a Fas/Fas liganddependent mechanism. J. Immunol. 177, 6540-6547 (2006).

83. Schefold, J. C. Measurement of monocytic HLA-DR (mHLA-DR) expression in patients with severe sepsis and septic shock: assessment of immune organ failure. Intensive Care Med. 36, 1810-1812 (2010).

84. Drewry, A. M. et al. Comparison of monocyte human leukocyte antigen-DR expression and stimulated tumor necrosis factor alpha production as outcome predictors in severe sepsis: a prospective observational study. Crit. Care 20, 334 (2016).

85. Wu, J. F. et al. Changes of monocyte human leukocyte antigen-DR expression as a reliable predictor of mortality in severe sepsis. Crit. Care 15, R220 (2011)

86. Cazalis, M. A. et al. Decreased HLA-DR antigen-associated invariant chain (CD74) mRNA expression predicts mortality after septic shock. Crit. Care $\mathbf{1 7}$ R287 (2013).

87. Andonegui, G. et al. Targeting inflammatory monocytes in sepsis-associated encephalopathy and long-term cognitive impairment. JCI Insight 3, 99364 (2018).

88. Hamers, L., Kox, M. \& Pickkers, P. Sepsis-induced immunoparalysis: mechanisms, markers, and treatment options. Minerva Anestesiol. 81, 426-439 (2015).

89. Gordon, S. \& Martinez, F. O. Alternative activation of macrophages: mechanism and functions. Immunity 32, 593-604 (2010).

90. Sica, A. \& Mantovani, A. Macrophage plasticity and polarization: in vivo veritas. J. Clin. Invest. 122, 787-795 (2012).

91. Benoit, M., Desnues, B. \& Mege, J. L. Macrophage polarization in bacterial infections. J. Immunol. 181, 3733-3739 (2008).

92. Peck-Palmer, O. M. et al. Modulation of the Bcl-2 family blocks sepsisinduced depletion of dendritic cells and macrophages. Shock $\mathbf{3 1}$ 359-366 (2009).

93. Reizis, B. Classical dendritic cells as a unique immune cell lineage. J. Exp. Med. 209, 1053-1056 (2012)

94. Baratin, M. et al. Homeostatic NF-kappaB signaling in steady-state migratory dendritic cells regulates immune homeostasis and tolerance. Immunity $\mathbf{4 2}$, 627-639 (2015).

95. Niessen, F. et al. Dendritic cell PAR1-S1P3 signalling couples coagulation and inflammation. Nature 452, 452654-452658 (2008).

96. Poehlmann, $\mathrm{H}$. et al. Phenotype changes and impaired function of dendritic cell subsets in patients with sepsis: a prospective observational analysis. Crit. Care 13, R119 (2009)

97. Mildner, A. \& Jung, S. Development and function of dendritic cell subsets. Immunity 40, 642-656 (2014).

98. Pietruczuk, M. et al. Alteration of peripheral blood lymphocyte subsets in acute pancreatitis. World J. Gastroenterol. 12, 5344-5351 (2006).

99. Grimaldi, D. et al. Profound and persistent decrease of circulating dendritic cells is associated with ICU-acquired infection in patients with septic shock Intensive Care Med. 37, 1438-1446 (2011)

100. Kumar, V. Dendritic cells in sepsis: potential immunoregulatory cells with therapeutic potential. Mol. Immunol. 101, 615-626 (2018).

101. Guisset, O. et al. Decrease in circulating dendritic cells predicts fatal outcome in septic shock. Intensive Care Med. 33, 148-152 (2007).

102. Strother, R. K. et al. Polymicrobial sepsis diminishes dendritic cell numbers and function directly contributing to impaired primary CD8 T cell responses in vivo. J. Immunol. 197, 4301-4311 (2016).

103. Pene, F. et al. Toll-like receptors 2 and 4 contribute to sepsis-induced depletion of spleen dendritic cells. Infect. Immun. 77, 5651-5658 (2009).

104. Elsayh, K. I. et al. Dendritic cells in childhood sepsis. J. Crit. Care 28, 881 e7-13 (2013)

105. Fan, $\mathrm{X}$. et al. Alterations of dendritic cells in sepsis: featured role in immunoparalysis. Biomed. Res. Int. 2015, 903720 (2015).

106. Pastille, E. et al. Modulation of dendritic cell differentiation in the bone marrow mediates sustained immunosuppression after polymicrobial sepsis. J. Immunol. 186, 977-986 (2011).

107. Faivre, V. et al. Human monocytes differentiate into dendritic cells subsets that induce anergic and regulatory T cells in sepsis. PLOS ONE 7, e47209 (2012)
108. Wu, D. D., Li, T. \& Ji, X. Y. Dendritic cells in sepsis: pathological alterations and therapeutic implications. J. Immunol. Res. 2017, 3591248 (2017).

109. Weber, G. F. et al. Analysis of circulating plasmacytoid dendritic cells during the course of sepsis. Surgery 158, 248-254 (2015).

110. Luan, Y. Y. et al. Insights into the apoptotic death of immune cells in sepsis. J. Interferon Cytokine Res. 35, 17-22 (2015).

111. Scumpia, P. O. et al. CD11c+ dendritic cells are required for survival in murine polymicrobial sepsis. J. Immunol. 175, 3282-3286 (2005).

112. Bohannon, J. et al. Dendritic cell modification of neutrophil responses to infection after burn injury. J. Immunol. 185, 2847-2853 (2010).

113. Gautier, E. L. et al. Enhanced dendritic cell survival attenuates lipopolysaccharide-induced immunosuppression and increases resistance to lethal endotoxic shock. J. Immunol. 180, 6941-6946 (2008).

114. Chiche, L. et al. The role of natural killer cells in sepsis. J. Biomed. Biotechnol. 2011, 986491 (2011).

115. Bohannon, J., Guo, Y. \& Sherwood, E. R. The role of natural killer cells in the pathogenesis of sepsis: the ongoing enigma. Crit. Care 16, 185 (2012).

116. Vivier, E. et al. Functions of natural killer cells. Nat. Immunol. 9, 503-510 (2008).

117. Poli, A. et al. CD56bright natural killer (NK) cells: an important NK cell subset. Immunology 126, 458-465 (2009).

118. Vivier, E. et al. Innate or adaptive immunity? The example of natural killer cells. Science 331, 44-49 (2011).

119. Stevenson, M. M. \& Riley, E. M. Innate immunity to malaria. Nat. Rev. Immunol. 4. 169-180 (2004).

120. Bjorkstrom, N. K. et al. Rapid expansion and long-term persistence of elevated NK cell numbers in humans infected with hantavirus. J. Exp. Med. 208, 13-21 (2011)

121. Arase, $\mathrm{H}$. et al. Direct recognition of cytomegalovirus by activating and inhibitory NK cell receptors. Science 296, 1323-1326 (2002).

122. Giamarellos-Bourboulis, E. J. Natural killer cells in sepsis: detrimental role for final outcome. Crit. Care Med. 42, 1579-1580 (2014)

123. Guo, Y. et al. The biology of natural killer cells during sepsis. Immunology $\mathbf{1 5 3}$ 190-202 (2018).

124. Forel, J. M. et al. Phenotype and functions of natural killer cells in critically-ill septic patients. PLoS ONE 7, e50446 (2012).

125. Venet, F. et al. Early assessment of leukocyte alterations at diagnosis of septic shock. Shock 34, 358-363 (2010).

126. Holub, M. et al. Lymphocyte subset numbers depend on the bacterial origin of sepsis. Clin. Microbiol. Infect. 9, 202-211 (2003).

127. Souza-Fonseca-Guimaraes, F. et al. Toll-like receptors expression and interferon-gamma production by NK cells in human sepsis. Crit. Care $\mathbf{1 6}$ R206 (2012).

128. Halstead, E. S. et al. Reduced frequency of CD56 dim CD16 pos natural killer cells in pediatric systemic inflammatory response syndrome/sepsis patients. Pediatr. Res. 74, 427-432 (2013)

129. Wesselkamper, S. C. et al. NKG2D is critical for NK cell activation in host defense against Pseudomonas aeruginosa respiratory infection. J. Immunol. 181, 5481-5489 (2008)

130. Inoue, S. et al. IL-15 prevents apoptosis, reverses innate and adaptive immune dysfunction, and improves survival in sepsis. J. Immunol. 184 1401-1419 (2010).

131. Limaye, A. P. et al. Cytomegalovirus reactivation in critically ill immunocompetent patients. JAMA 300, 413-422 (2008).

132. Hsu, J. et al. Contribution of NK cells to immunotherapy mediated by PD-1/ PD-L1 blockade. J. Clin. Invest. 128, 4654-4668 (2018).

133. Patil, N. K. et al. Targeting immune cell checkpoints during sepsis. Int. J. Mol. Sci. 18, E2413 (2017)

134. Kumar, V. Natural killer cells in sepsis: underprivileged innate immune cells. Eur. J. Cell Biol. 98, 81-93 (2019).

135. Taniguchi, T. et al. Malaria protection in beta 2-microglobulin-deficient mice lacking major histocompatibility complex class I antigens: essential role of innate immunity, including gammadelta T cells. Immunology 122, 514-521 (2007)

136. Zheng, J. et al. $\gamma \delta-T$ cells: an unpolished sword in human anti-infection immunity. Cell Mol. Immunol. 10, 50-57 (2013).

137. Heffernan, D. S. et al. A divergent response of innate regulatory T-cells to sepsis in humans: circulating invariant natural killer T-cells are preserved. Hum. Immunol. 75, 277-282 (2014).

138. Andreu-Ballester, J. C. et al. Association of gammadelta T cells with disease severity and mortality in septic patients. Clin. Vaccin. Immunol. 20, 738-746 (2013). 
139. Douglas, J. J., Tsang, J. L. \& Walley, K. R. Sepsis and the innate-like response. Intensive Care Med. 40, 249-251 (2014).

140. Tschop, J. et al. Gammadelta T cells mitigate the organ injury and mortality of sepsis. J. Leukoc. Biol. 83, 581-588 (2017)

141. Heffernan, D. S. et al. Inflammatory mechanisms in sepsis: elevated invariant natural killer T-cell numbers in mouse and their modulatory effect on macrophage function. Shock 40, 122-128 (2013).

142. Liao, X. L. et al. Phenotypic changes and impaired function of peripheral gammadelta T cells in patients with sepsis. Shock 48, 321-328 (2017).

143. Chung, C. S. et al. Deficiency of gammadelta T lymphocytes contributes to mortality and immunosuppression in sepsis. Am. J. Physiol. Regul. Integr. Comp. Physiol. 291, R1338-1343 (2006)

144. Wang, $L$. et al. Antibacterial effect of human $V$ gamma $2 \mathrm{~V}$ delta $2 \mathrm{~T}$ cells in vivo. J. Clin. Invest. 108, 1349-1357 (2001).

145. Hu, Y. M. et al. Glutamine administration modulates lung gammadelta T lymphocyte expression in mice with polymicrobial sepsis. Shock 41, 115-122 (2014).

146. Pepper, M. \& Jenkins, M. K. Origins of CD4+ effector and central memory T cells. Nat. Immunol. 12, 467-471 (2011)

147. Jensen, I. J. et al. Sepsis-induced T cell immunoparalysis: the ins and outs of impaired T cell immunity. J. Immunol. 200, 1543-1553 (2018).

148. Gutcher, I. \& Becher, B. APC-derived cytokines and T cell polarization in autoimmune inflammation. J. Clin. Invest. 117, 1119-1127 (2007).

149. Kasten, K. R. et al. T-cell activation differentially mediates the host response to sepsis. Shock 34, 377-383 (2010).

150. Gouel-Cheron, A. et al. CD4+ T-lymphocyte alterations in trauma patients. Crit. Care 16, 432 (2012).

151. Inoue, S. et al. Reduction of immunocompetent T cells followed by prolonged lymphopenia in severe sepsis in the elderly. Crit. Care Med. 41, 810-819 (2013).

152. Heffernan, D. S. et al. Failure to normalize lymphopenia following trauma is associated with increased mortality, independent of the leukocytosis pattern. Crit. Care 16, R12 (2012).

153. Shindo, Y. et al. Interleukin-7 and anti-programmed cell death 1 antibody have differing effects to reverse sepsis-induced immunosuppression. Shock 43, 334-343 (2015)

154. Widera, A. Physics. A walk across a quantum lattice. Science 347, 1200-1201 (2015).

155. Mackall, C. L., Fry, T. J. \& Gress, R. E. Harnessing the biology of IL-7 for therapeutic application. Nat. Rev. Immunol. 11, 330-342 (2011).

156. Unsinger, J. et al. IL-7 promotes T cell viability, trafficking, and functionality and improves survival in sepsis. J. Immunol. 184, 3768-3779 (2010).

157. Singh, A. et al. Inhibiting the programmed death 1 pathway rescues Mycobacterium tuberculosis-specific interferon gamma-producing $\mathrm{T}$ cells from apoptosis in patients with pulmonary tuberculosis. J. Infect. Dis. 208, 603-615 (2013).

158. Crouser, E. D. \& Hotchkiss, R. S. Desperate times call for desperate measures: self-cannibalism is protective during sepsis. Crit. Care Med. 45, 145-147 (2017).

159. Ono, S. et al. Mechanisms of sepsis-induced immunosuppression and immunological modification therapies for sepsis. Ann. Gastroenterol. Surg. 2 351-358 (2018).

160. Inoue, S. et al. Persistent inflammation and T cell exhaustion in severe sepsis in the elderly. Crit. Care 18, R130 (2014).

161. Guignant, C. et al. Programmed death-1 levels correlate with increased mortality, nosocomial infection and immune dysfunctions in septic shock patients. Crit. Care 15, R99 (2011).

162. Huang, X. et al. PD-1 expression by macrophages plays a pathologic role in altering microbial clearance and the innate inflammatory response to sepsis. Proc. Natl Acad. Sci. USA 106, 6303-6308 (2009).

163. Chang, K. C. et al. Blockade of the negative co-stimulatory molecules PD-1 and CTLA-4 improves survival in primary and secondary fungal sepsis. Crit. Care 17, R85 (2013).

164. Chang, K. et al. Targeting the programmed cell death 1: programmed cell death ligand 1 pathway reverses $T$ cell exhaustion in patients with sepsis. Crit. Care 18, R3 (2014).

165. Mauri, C. \& Bosma, A. Immune regulatory function of B cells. Annu. Rev. Immunol. 30, 221-241 (2012).

166. Rauch, P. J. et al. Innate response activator B cells protect against microbial sepsis. Science 335, 597-601 (2012).

167. Monserrat, J. et al. Early alterations of B cells in patients with septic shock. Crit. Care 17, R105 (2013).
168. Kelly-Scumpia, K. M. et al. B cells enhance early innate immune responses during bacterial sepsis. J. Exp. Med. 208, 1673-1682 (2011).

169. Fillatreau, S. et al. B cells regulate autoimmunity by provision of IL-10. Nat. Immunol. 3, 944-950 (2002).

170. Mizoguchi, A. et al. Chronic intestinal inflammatory condition generates IL10-producing regulatory $B$ cell subset characterized by CD1d upregulation. Immunity 16, 219-230 (2002).

171. Vaughan, A. T., Roghanian, A. \& Cragg, M. S. B cells-masters of the immunoverse. Int. J. Biochem. Cell Biol. 43, 280-285 (2011).

172. Rawlings, D. J. et al. Integration of B cell responses through Toll-like receptors and antigen receptors. Nat. Rev. Immunol. 12, 282-294 (2012).

173. Shankar-Hari, M. et al. Activation-associated accelerated apoptosis of memory B cells in critically ill patients with sepsis. Crit. Care Med. 45 875-882 (2017)

174. Hotchkiss, R. S. et al. Sepsis-induced apoptosis causes progressive profound depletion of B and CD4+ T lymphocytes in humans. J. Immunol. 166, 6952-6963 (2001).

175. Brinkhoff, A. et al. B cell dynamics during experimental endotoxemia in humans. Biosci. Rep. 39, BSR20182347 (2019).

176. Peck-Palmer, O. M. et al. Deletion of MyD88 markedly attenuates sepsisinduced T and B lymphocyte apoptosis but worsens survival. J. Leukoc. Biol. 83, 1009-1018 (2008).

177. Deng, Q. et al. Protective effect of tubastatin A in CLP-induced lethal sepsis. Inflammation 41, 2101-2109 (2018).

178. Liston, A. \& Gray, D. H. Homeostatic control of regulatory T cell diversity. Nat. Rev. Immunol. 14, 154-165 (2014).

179. Sakaguchi, S. et al. Regulatory T cells and immune tolerance. Cell 133, 775-787 (2008).

180. Tanoue, T., Atarashi, K. \& Honda, K. Development and maintenance of intestinal regulatory T cells. Nat. Rev. Immunol. 16, 295-309 (2016).

181. Cao, C. et al. The role of regulatory $\mathrm{T}$ cells in immune dysfunction during sepsis. World J. Emerg. Med. 6, 5-9 (2015).

182. Monneret, G. et al. Marked elevation of human circulating CD4+CD25+ regulatory $\mathrm{T}$ cells in sepsis-induced immunoparalysis. Crit. Care Med. 31, 2068-2071 (2003).

183. Venet, F. et al. Increased circulating regulatory T cells (CD4(+)CD25 (+)CD127 $(-))$ contribute to lymphocyte anergy in septic shock patients. Intensive Care Med. 35, 678-686 (2009).

184. Cavassani, K. A. et al. The post sepsis-induced expansion and enhanced function of regulatory $\mathrm{T}$ cells create an environment to potentiate tumor growth. Blood 115, 4403-4411 (2010).

185. Venet, F. et al. Regulatory T cell populations in sepsis and trauma. J. Leukoc. Biol. 83, 523-535 (2008).

186. Leng, F. Y. et al. Increased proportion of CD4(+)CD25(+)Foxp3(+) regulatory $\mathrm{T}$ cells during early-stage sepsis in ICU patients. J. Microbiol. Immunol. Infect. 46, 338-344 (2013).

187. Cao, C. et al. Toll-like receptor 4 deficiency increases resistance in sepsisinduced immune dysfunction. Int. Immunopharmacol. 54, 169-176 (2018).

188. Cao, C. et al. Ulinastatin mediates suppression of regulatory $T$ cells through TLR4/NF-kappaB signaling pathway in murine sepsis. Int. Immunopharmacol. 64, 411-423 (2018).

189. Carrigan, S. O. et al. Depletion of natural CD4+CD25+ T regulatory cells with anti-CD25 antibody does not change the course of Pseudomonas aeruginosa-induced acute lung infection in mice. Immunobiology 214, 211-222 (2009).

190. Venet, F. et al. Monitoring the immune response in sepsis: a rational approach to administration of immunoadjuvant therapies. Curr. Opin. Immunol. 25, 477-483 (2013).

191. Hotchkiss, R. S. et al. Overexpression of BCl-2 in transgenic mice decreases apoptosis and improves survival in sepsis. J. Immunol. 162, 4148-4156 (1999).

192. Watanabe, E., Thampy, L. K. \& Hotchkiss, R. S. Immunoadjuvant therapy in sepsis: novel strategies for immunosuppressive sepsis coming down the pike. Acute Med. Surg. 5, 309-315 (2018).

193. Hutchins, N. A. et al. The new normal: immunomodulatory agents against sepsis immune suppression. Trends Mol. Med. 20, 224-233 (2014).

194. Francisco-Cruz, A. et al. Granulocyte-macrophage colony-stimulating factor: not just another haematopoietic growth factor. Med. Oncol. 31, 774 (2014).

195. Meisel, C. et al. Granulocyte-macrophage colony-stimulating factor to reverse sepsis-associated immunosuppression: a double-blind, 
randomized, placebo-controlled multicenter trial. Am. J. Respir. Crit. Care Med. 180, 640-648 (2009).

196. Hall, M. W. et al. Immunoparalysis and nosocomial infection in children with multiple organ dysfunction syndrome. Intensive Care Med. 37, 525-532 (2011).

197. Docke, W. D. et al. Monocyte deactivation in septic patients: restoration by IFN-gamma treatment. Nat. Med. 3, 678-681 (1997).

198. Nalos, M. et al. Immune effects of interferon gamma in persistent staphylococcal sepsis. Am. J. Respir. Crit. Care Med. 185, 110-112 (2012).

199. Zhang, Y. et al. PD-L1 blockade improves survival in experimental sepsis by inhibiting lymphocyte apoptosis and reversing monocyte dysfunction. Crit. Care 14, R220 (2018).
200. Zhang, Y. et al. Upregulation of programmed death-1 on T cells and programmed death ligand-1 on monocytes in septic shock patients. Crit. Care 15, R70 (2011)

201. Pellegrini, M. et al. LL-7 engages multiple mechanisms to overcome chronic viral infection and limit organ pathology. Cell 144, 601-613 (2011).

202. Yang, X. et al. T cell lg mucin-3 promotes homeostasis of sepsis by negatively regulating the TLR response. J. Immunol. 190, 2068-2079 (2013).

203. Zhao, Z. et al. Blockade of the $T$ cell immunoglobulin and mucin domain protein 3 pathway exacerbates sepsis-induced immune deviation and immunosuppression. Clin. Exp. Immunol. 178, 279-291 (2014).

204. Inoue, S. et al. Dose-dependent effect of anti-CTLA-4 on survival in sepsis. Shock 36, 38-44 (2011). 